$\underline{\text { Three Minute Article for Parents }}$

\title{
Screening of children with anaemia for iron deficiency and thalassaemia trait provides an opportunity for thalassaemia prevention in Sri Lanka
}

Sachith Mettananda iD https://orcid.org/0000-0002-0760-0418

Sri Lanka Journal of Child Health, 2021; 50(2): 369

DOI: http://dx.doi.org/10.4038/sljch.v50i2.9597

(Key words: Screening, children, anaemia, iron deficiency, thalassaemia trait, Sri Lanka)

Anaemia or reduced haemoglobin is a common medical problem in children. The World Health Organisation estimates that over one-third of the world population suffer from anaemia. The prevalence of anaemia among children in Sri Lanka is reported as $15 \%$.

The causes of anaemia are numerous. However, most people consider iron deficiency as the single most important cause for anaemia in children. In fact, the term 'anaemia' is used erroneously to describe 'iron deficiency' by many people. This misconception is present not only among the lay people but among health professionals, too ${ }^{1}$.

We recently conducted a detailed evaluation of 104 children with anaemia at the Colombo North Teaching Hospital, Ragama, Sri Lanka, to identify relative contributions of various causes of anaemia ${ }^{2}$. In that study, we found iron deficiency to account for only $49 \%$ of children with anaemia. Importantly, thalassaemia trait was the cause for anaemia in $26 \%$ of children; $16 \%$ had $\alpha$-thalassaemia trait and $10 \%$ had $\beta$-thalassaemia trait.

Thalassaemia trait refers to the carrier state of a thalassaemia gene. $\alpha$-thalassaemia trait is not a medically significant problem in Sri Lanka. Nonetheless, identification of $\beta$-thalassaemia trait is essential in preventing births of children with 'thalassaemia disease'. Humans have two $\beta$-globin genes in every cell and the thalassaemia disease is caused by inheriting two mutated genes. Inheritance of one mutated gene and one normal gene results in $\beta$-thalassaemia trait ${ }^{3}$. Individuals with $\beta$ thalassaemia trait do not show symptoms and are only identified through blood investigations. However, a marriage of two individuals with $\beta$ thalassaemia trait results in a one in four risk of having a child with thalassaemia disease by inheriting two mutated genes, one from each parent. In order to prevent this, it is essential to identify individuals with $\beta$-thalassaemia trait and avoid marriages between them. Therefore, our study showed that parallel screening of children with anaemia for iron deficiency and thalassaemia trait provides a valuable opportunity for thalassaemia prevention in Sri Lanka.
The take home message is that testing for thalassaemia trait in children and young people is a strategy that could be usefully employed to prevent 'thalassaemia disease'.

\section{References}

1. Mettananda S, de Silva DG. Anaemia in children: are we using the correct prevention strategies? Ceylon Medical Journal 2017; 62(2):73-6.

2. Mettananda S, Paranamana S, Fernando R, Suranjan M, Rodrigo R, Perera L, et al. Microcytic anaemia in children: parallel screening for iron deficiency and thalassaemia provides a useful opportunity for thalassemia prevention in low- and middle-income countries. Pediatric Hematology and Oncology 2020:1-11

3. Mettananda S. Management of thalassaemia. Sri Lanka Journal of Child Health 2018; 47(2): 159-65.

Open Access Article published under the Creative Commons Attribution CC-BY (C) (i) License 